\title{
Novel imidazo[1,2-a]pyridine inhibits AKT/mTOR pathway and induces cell cycle arrest and apoptosis in melanoma and cervical cancer cells
}

\author{
SAEB ALIWAINI ${ }^{1}$, ADEL M. AWADALLAH ${ }^{2}$, RAMI Y. MORJAN $^{2}$, MARIAM GHUNAIM $^{1}$, HALA ALQADDI $^{1}$, \\ ASMAA Y. ABUHAMAD ${ }^{1}$, ENAS A. AWADALLAH ${ }^{1}$ and YASMIN M. ABUGHEFRA ${ }^{1}$ \\ Departments of ${ }^{1}$ Biology and Biotechnology and ${ }^{2}$ Chemistry, Islamic University of Gaza, 108 Gaza, Palestine
}

Received October 23, 2018; Accepted April 5, 2019

DOI: $10.3892 / \mathrm{ol} .2019 .10341$

\begin{abstract}
The present study aimed to investigate the anti-cancer activity of imidazo[1,2-a]pyridine 5-7 in the A375 and WM115 melanoma and HeLa cervical cancer cell lines. The viability of cancer cells was analyzed by the MTT assay. Apoptosis was quantified by flow cytometry following staining of the cells with AnnexinV/propidium iodide (PI). The cell cycle was evaluated by flow cytometry after staining of cells with PI. The three compounds inhibited the proliferation of all cells for half maximal inhibitory concentration ranging from 9.7 to $44.6 \mu \mathrm{M}$ following 48-h treatment. In addition, all cancer cells were more sensitive to compound 6 compared with the other compounds. Treatment with compound 6 induced $\mathrm{G}_{2} / \mathrm{M}$ cell cycle arrest and a significant increased level of intrinsic apoptosis in all tested cells. Furthermore, compound 6 reduced the levels of phospho (p)-protein kinase $\mathrm{B}$ and $\mathrm{p}$-mechanistic target of rapamycin, and increased levels of the cell cycle inhibitors p53 and p21 and of the apoptosis-associated proteins BCL2 associated X protein and active caspase-9. Silencing p53 in A375 melanoma cells reduced compound 6-induced apoptosis, which suggested that compound 6 may induce p53-partially mediated apoptosis. These results demonstrated that imidazo[1,2-a]pyridines 5-7 are potential effective compounds in the treatment of melanoma and cervical cancers.
\end{abstract}

\section{Introduction}

Cervical cancer and melanoma are aggressive cancers with increasing incidence worldwide (1). Whereas cervical cancer

Correspondence to: Dr Saeb Aliwaini, Department of Biology and Biotechnology, Islamic University of Gaza, Rimal Street, 108 Gaza, Palestine

E-mail: saib.iwini@gmail.com

Key words: imidazo[1,2-a]pyridine, melanoma, cervical cancer, apoptosis, p53 ranks fourth cancer for both incidence and mortality, malignant melanoma is the most serious type of skin cancer and accounts for the majority of skin cancer-associated mortalities $(1,2)$. Cervical cancer is commonly treated with a combination of radiotherapy and platinum-based chemotherapy, which may also damage normal cells (3). At present, there is no globally accepted standard treatment that offers a significant survival benefit for patients with advanced-stage melanoma (2). Until 2011, the chemotherapeutic drugs dacarbazine, temozolomide and fotemustine were most commonly used for metastatic melanoma treatment (4); however, only a low percentage of patients who received these compounds exhibited a significant response. These treatments have been mostly replaced by the immune-checkpoint inhibitors, including cytotoxic T-lymphocyte-associated protein-4 (CTLA-4), B-Raf proto-oncogene (BRAF) and mitogen-activated protein kinase kinase (MEK) inhibitors (5). However, these therapeutic alternatives display adverse events, including secondary cutaneous squamous cell carcinomas and keratoacanthomas, which occur in $\sim 20 \%$ of patients treated with BRAF-inhibitor (6). A previous study reported that MEK inhibitors have more serious adverse effects and a lower efficacy compared with BRAF inhibitors (5). The development of novel effective agents for the treatment of these cancers is therefore crucial.

Imidazopyridines possess a wide range of biological activities. In particular, the imidazo[1,2-a]pyridine moieties of imidazopyridine have recently gained significant interest as potential anticancer agents due to their potent inhibitory role of cancer cell growth, which is commonly due to survival kinases inhibition $(7,8)$. Various drugs containing imidazo[1,2-a]pyridine moieties are currently used to treat cardiac disorders, insomnia, antianxiety, ulcers and HIV infections (9). Although these compounds have numerous medicinal applications, none of them have been accepted as an anti-cancer drug. However, previous studies have reported that imidazo[1,2-a]pyridines have some anti-cancer abilities. For example, Goel et al (9) recently reported that 3-\{1-[(4-fluorophenyl)sulfonyl]-1H-pyrazol3-yl\}-2-methylimimoredazo[1,2-a]pyridine may be a novel PIK3CA inhibitor with an half maximal inhibitory concentration $\left(\mathrm{IC}_{50}\right)$ of $0.67 \mu \mathrm{M}$. Further optimization of the substituents resulted in thiazole groups substituted by 
imidazo[1,2-a]pyridines, which are more potent inhibitor of phosphatidylinositol-4,5-bisphosphate 3-kinase catalytic subunit alpha (PI3KCA) with an $\mathrm{IC}_{50}$ of $0.0028 \mu \mathrm{M}(10)$. In addition, this compound exerts a promising anti-proliferation effect against melanoma (A375) and cervical (HeLa) cancer cells, with $\mathrm{IC}_{50}$ values of 0.14 and $0.21 \mu \mathrm{M}$, respectively. Notably, $50 \mathrm{mg} / \mathrm{kg}$ of this compound significantly inhibits HeLa human cervical tumor xenografts growth in mice. Additional series of imidazo[1,2-a]pyridine derivatives were designed and synthesized as PI3K $\alpha$ inhibitors (6). One of these compounds, comprising the bioisosteric 1,2,4-oxadiazole group as a substituent, exhibits potent $\mathrm{PI} 3 \mathrm{~K} \alpha$ inhibition with an $\mathrm{IC}_{50}$ of $2 \mathrm{nM}$. In addition, this compound inhibits various types of breast cancer cell line proliferation with an $\mathrm{IC}_{50}$ of $>10 \mu \mathrm{M}$. Furthermore, Annexin $\mathrm{V}$ results demonstrated that it significantly increases T47D breast cancer cell apoptosis. At a molecular level, these effects are associated with PI3K signaling inhibition. Notably, this compound has some anti-angiogenic effects through VEGF expression inhibition. In addition, ethyl 6-(5-(phenyl sulfonamide)pyridin-3-yl)imidazo[1,2-a] pyridine-3-carboxylate was also reported (11). This compound has significant anti-cancer activity in non-small cell lung cancer cells. Cell treatment with this compound inhibits the phospho (p)-protein kinase B (PI3K)-protein kinase B (Akt)-mechanistic target of rapamycin (mTOR) pathway-induced intrinsic apoptosis (11). A recent study reported that selenylated imidazo[1,2-a]pyridines inhibits breast cancer cell proliferation by inducing DNA damage and apoptosis (12). Additional anti-cancer properties of imidazo[1,2-a]pyridines, including inhibition of nicotinamide phosphoribosyltransferase (13), cyclin-dependent kinases (14) and insulin-like growth factor 1 receptor tyrosine kinase (8) were also reported.

The present study aimed to investigated the anticancer activities of three imidazo[1,2-a]pyridines, the compounds 5-7, in melanoma and cervical cancer cells through analyses of the Akt/mTOR pathway, the cell cycle and apoptosis.

\section{Materials and methods}

Chemicals and reagents. Chemicals and solvents, radioimmunoprecipitation assay (RIPA) lysis buffer (cat. no. R0278) were used without further purification and were supplied by Sigma-Aldrich; Merck KGaA (Darmstadt, Germany), unless otherwise stated. Media and cell culture reagents were from Biological Industries (Kibbutz Beit Haemek, Israel). Western blotting reagents were obtained from Bio-Rad Laboratories Inc. (Hercules, CA, USA). DAPI and primary antibodies against poly(ADP-ribose) polymerase 1/2 (PARP1/2; cat. no. sc-7150), p53 (cat. no. sc-126), p21 (cat. no. sc-756), BCL2 associated X protein (BAX; cat. no. sc-7480), cyclin B (cat. no. sc-sc-53236), AKT (cat. no. sc-514032) and tubulin (cat. no. sc-5286) were purchased from Santa Cruz Biotechnology, Inc. (Dallas, TX, USA). Primary antibodies against B-cell lymphoma 2 (BCL2; cat. no. 2876) and caspase-9 (cat. no. 9502) were provided by Cell Signaling Technology, Inc. (Danvers, MA, USA). Horseradish peroxidase-conjugated secondary antibodies were provided by Bio-Rad Laboratories, Inc. (Hercules, CA, USA) and electrochemiluminescence reaction (ECL) detection system was purchased from Thermo Fisher Scientific, Inc. (Waltham, MA, USA).

Synthesis of compounds 5-7. Triethylamine (0.6 g, $0.006 \mathrm{~mol})$ diluted in $10 \mathrm{ml}$ dry tetrahydrofuran (THF) was dropwise added to a stirring solution of hydrazonoyl chloride $1(0.005 \mathrm{~mol})$ and substituted picolines 2-4 (0.65 g, $0.006 \mathrm{~mol})$ in $25 \mathrm{ml} \mathrm{THF}$ at room temperature. Stirring was continued overnight, and the solvent was evaporated in vacuo. The residual solid was washed with water to remove the triethylammonium salt, and the crude products were recrystallized from the appropriate solvents to obtain the compounds 5-7. The physical data of these compounds are available in the original publication (15). The chemical formulas of the three compounds were as follows: 3-[(4-Chlorophenyl)diazenyl]-2,8-dimethylimidazo[1,2-a]pyridine (compound 5), 3-[(4-Chlorophenyl) diazenyl]-2,7-dimethylimidazo[1,2-a]pyridine (compound 6) and 3-[(4-Chlorophenyl)diazenyl]-2,5-dimethylimidazo[1,2a]pyridine (compound 7).

Cell culture and treatments. The human melanoma cell lines A375 and WM115 and the cervical cancer cell line HeLa, sourced from the Department of Human Biology, University of Cape Town (Cape Town, South Africa), were maintained in Dulbecco's modified Eagle's medium supplemented with $10 \%$ fetal bovine serum and placed at $37^{\circ} \mathrm{C}$ in a humidified incubator containing 5\% $\mathrm{CO}_{2}$. Compounds 5-7 were dissolved in dimethyl sulfoxide (DMSO) to obtain $10 \mathrm{mM}$ stock solutions that were stored at room temperature for a maximum of 10 days. Control cells were treated with equivalent concentrations of DMSO (vehicle).

Small interfering RNA (siRNA). Suppression of p53 expression was achieved by siRNA that specifically targeted p53 mRNA. Cells at $70 \%$ confluence were transfected with $50 \mathrm{nM}$ anti-p53 siRNA (cat. no. sc-756) or a scrambled control RNA (cat. no. sc-37007) from Santa Cruz Biotechnology, Inc. (Dallas, TX, USA) using Lipofectamine ${ }^{\circledR} 2000$ (Thermo Fisher Scientific, Inc.) according to the manufacturer's instructions. The transfection reagent and siRNA complex were added drop-wise to the cells and incubated for $30 \mathrm{~h}$ at $37^{\circ} \mathrm{C}$. The subsequent experiments were performed $30 \mathrm{~h}$ after transfection.

Cytotoxicity assays. Cells were seeded in 96-well plates at $4-5 \times 10^{3}$ cells per well and allowed to settle for $48 \mathrm{~h}$. Cells were treated with increasing concentrations of compounds 5-7 $(0-100 \mu \mathrm{M})$ or vehicle for $48 \mathrm{~h}$. Cytotoxicity was assessed using MTT assay (Roche Diagnostics GmbH, Mannheim, Germany) (16) according to the manufacturer's instructions. Briefly, $10 \mu \mathrm{l}$ MTT solution was added to each well and cells were incubated at $37^{\circ} \mathrm{C}$ for $4 \mathrm{~h}$. The solubilization buffer (100 $\mu 1,10 \%$ SDS in $0.01 \mathrm{M}$ hydrochloric acid) was added on cells for $16 \mathrm{~h}$ at $37^{\circ} \mathrm{C}$. Absorbance was determined at $585 \mathrm{~nm}$ with a microplate reader, and the mean cell viability was calculated as a percentage of the mean vehicle control.

Cell cycle analysis. The effect of compound 6 on the cell cycle profile of cancer cells was determined according to a previous protocol (17). Briefly, cells were seeded at $3-4 \times 10^{5}$ cells per 
<smiles>CC(=O)/C(Cl)=N/Nc1ccc(Cl)cc1</smiles>

1<smiles>Cc1cccc(N)n1</smiles>
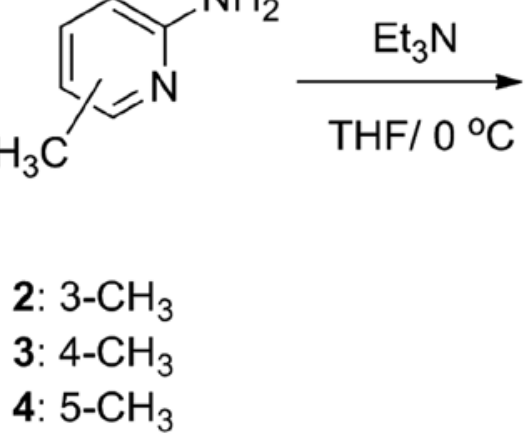

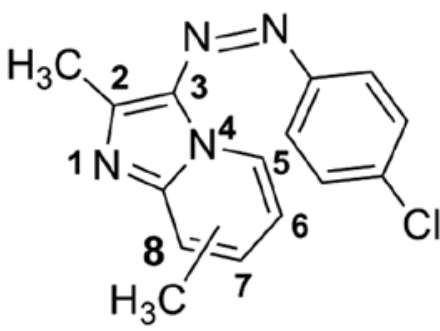

$$
\begin{aligned}
& \text { 5: } 8-\mathrm{CH}_{3} \\
& \text { 6: } 7-\mathrm{CH}_{3} \\
& \text { 7: } 5-\mathrm{CH}_{3}
\end{aligned}
$$

Figure 1. Schematic representation of the imidazo[1,2-a]pyridines 5-7 compounds synthesis and structures $(15)$. Et ${ }_{3} \mathrm{~N}$, triethylamine; THF, tetrahydrofuran.

6-cm dish and allowed to settle for $24 \mathrm{~h}$. Log-phase cultures were exposed to compounds 5-7 (0 to $100 \mu \mathrm{M})$ or vehicle for 48 h. Cells were trypsinized, washed with PBS and fixed overnight in $95 \%$ ethanol at $4^{\circ} \mathrm{C}$, and subjected to RNase treatment and stained for $30 \mathrm{~min}$ at room temperature with propidium iodide (PI; $500 \mu \mathrm{g} / \mathrm{ml}$; Sigma-Aldrich; Merck KGaA). Cellular DNA content was determined by flow cytometry with a FACSCalibur flow cytometer with a $488 \mathrm{~nm}$ Coherent laser (BD Biosciences, Franklin Lakes, NJ, USA). The CellQuest Pro version 5.2.1 software (BD Biosciences) was used for data acquisition and analyses were performed using Modfit version 2.0 software (BD Biosciences).

Detection of apoptosis. Log-phase cultures (60-70\% confluence) were treated with compound 6 or vehicle for $48 \mathrm{~h}$. Adherent and floating cells were collected and double-labelled with Annexin V-Fluorescein isothiocyanate (FITC) and PI (Sigma-Aldrich; Merck KGaA) for $10 \mathrm{~min}$ at room temperature. Annexin V-FITC was used to determine apoptotic cells percentage whereas PI stained all dead cells. Cells were analyzed by flow cytometry with a $488 \mathrm{~nm}$ Coherent laser equipped with FACStation running CellQuest software (BD Biosciences).

Nuclear fragmentation. Melanoma and cervical cancer cells were treated with compound 6 (10 and $35 \mu \mathrm{M}$, respectively) for $24 \mathrm{~h}$ at $37^{\circ} \mathrm{C}$ and stained with DAPI $(10 \mu \mathrm{g} / \mathrm{ml})$ nuclear stain for $10 \mathrm{~min}$ at room temperature. Cells were observed by fluorescence microscopy (Zeiss GmbH, Jena, Germany).

Western blotting. Cells were harvested with RIPA lysis buffer for $30 \mathrm{~min}$ on ice. The lysates were collected, and the protein concentrations were determined using Bradford's reagent (Bio-Rad Laboratories, Inc.), according to the manufacturer's instructions and using albumin as a standard. A total of $20 \mu \mathrm{g}$ protein was separated by $8-15 \%$ SDS-PAGE, and transferred to a Hybond ECL nitrocellulose membrane (GE Healthcare, Chicago, IL, USA) (17). Following blocking for $1 \mathrm{~h}$ at room temperature with PBS containing 0.05\% Tween-20 and $5 \%$ powdered skim milk, membranes were incubated overnight with primary antibodies $(1: 1,000)$ at $4^{\circ} \mathrm{C}$. After primary antibody incubation, membranes were incubated with appropriate HRP-conjugated secondary antibodies $(1: 5,000)$ for $1 \mathrm{~h}$ at room temperature. Bands were detected using enhanced chemiluminescence detection system (Thermo Fisher Scientific, Inc., Waltham, MA, USA) (18). Relative expression level of the proteins was analyzed by UN-SCAN-IT gel 6.1 software by Silk Scientific Corporation (Orem, UT, USA) and normalized to the loading controls.

Statistical analysis. Results are presented as the mean \pm standard error of the mean (SEM) of the three independent experiments. Statistical analysis of data was performed using the two-sample t-test in Microsoft Excel 2013 (Microsoft Corporation, Redmond, WA, USA) or a one-way ANOVA with Tukey's post hoc test in Graph Pad Prism (version 5; GraphPad Software, Inc., La Jolla, CA, USA). $\mathrm{P}<0.05$ was considered to indicate a statistically significant difference.

\section{Results}

Imidazo[1,2-a]pyridines induces cytotoxicity and cell cycle arrest. Imidazo[1,2-a]pyridines 5-7 were synthesized according to our published method (15). As presented in Fig. 1, the reaction of hydrazonoyl chloride 1 with the appropriate substituted methyl-2-aminopicolines 2-4 in the presence of triethylamine as a base at $0^{\circ} \mathrm{C}$ gave the compounds 5-7 (Fig. 1).

The cytotoxic effects of compounds 5-7 on melanoma and cervical cancer cell lines were investigated. A375, WM115 and HeLa cells were treated with increasing concentration of compounds 5-7 (0 to $100 \mu \mathrm{M})$ for $48 \mathrm{~h}$ prior to assessing cell viability with MTT assay. The results demonstrated that all compounds inhibited cell proliferation of the three cell lines with different $\mathrm{IC}_{50}$ ranging from 9.7 to $44.6 \mu \mathrm{M}$ (Fig. 2A). Notably, compound 6 was the most potent compound to induce melanoma and cervical cancer cell toxicity. In addition, compound 6 was more toxic to melanoma cells than cervical cancer cells. The effect of compound 6 on cell cycle profile was then explored. To do so, melanoma and cervical cancer cells were treated with 10 and $35.0 \mu \mathrm{M}$ compound 6, respectively, for $48 \mathrm{~h}$ prior to analyzing cell cycle. The results in Fig. 2B and C demonstrated that compound 6 induced a significant $\mathrm{G}_{2} / \mathrm{M}$ cell cycle arrest in all cell lines, which was mainly at the expense of $G_{1}$ phase cell populations. In addition, A375 cell treatment with compound 6 caused an increase in the cell population 
A

\begin{tabular}{|l|c|c|c|}
\hline \multirow{2}{*}{ Compound } & \multicolumn{3}{|c|}{ IC $_{50}$} \\
\cline { 2 - 4 } & HeLa & A375 & WM115 \\
\hline Compound 5 & $44.697 \pm 4.732$ & $33.370 \pm 4.380$ & $33.900 \pm 5.793$ \\
\hline Compound 6 & $37.841 \pm 3.324$ & $9.7346 \pm 2.435$ & $11.346 \pm 2.459$ \\
\hline Compound 7 & $42.036 \pm 2.603$ & $19.941 \pm 4.267$ & $22.458 \pm 1.293$ \\
\hline
\end{tabular}

B Control cells Treated cells

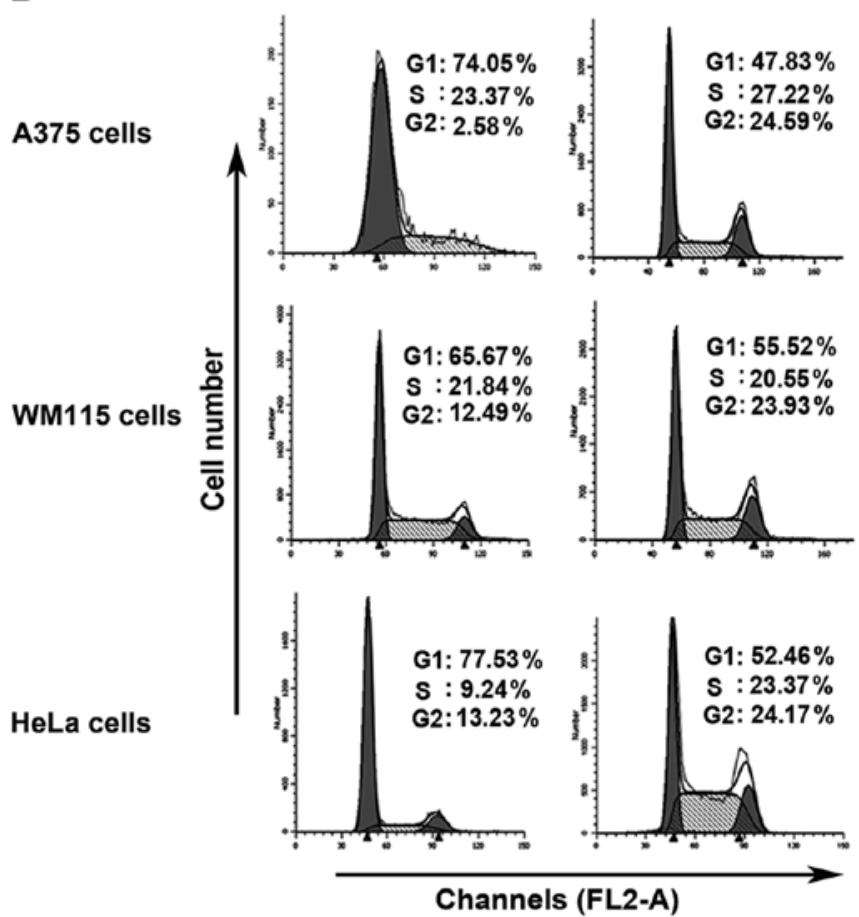

C

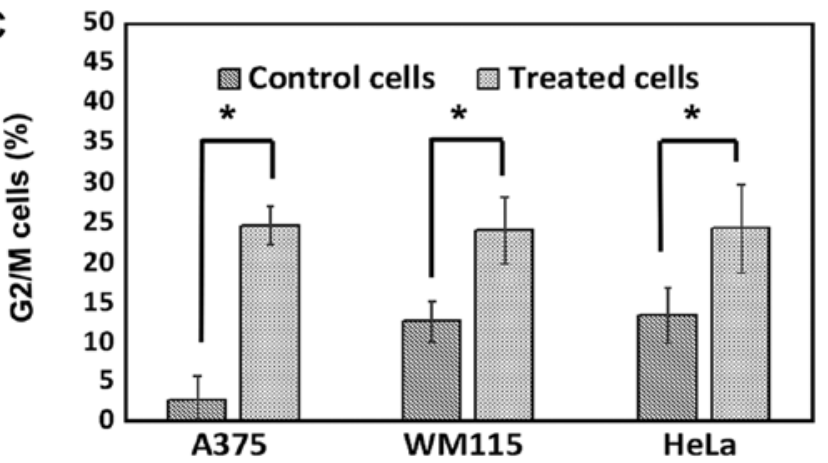

Figure 2. Compounds 5-7 inhibit cancer cell proliferation. (A) $\mathrm{IC}_{50}$ values for the treatment of A375, WM115 and HeLa cell lines with compound 6 for $48 \mathrm{~h}$. Cell survival rate was measured by MTT assay and $\mathrm{IC}_{50}$ values were calculated from sigmoidal plots with GraphPad Prism version 5. Results represented the means \pm standard error of the mean of at least three experiments performed in quadruplicate. (B) A375 and WM115 cells were treated with vehicle or compound $6(10 \mu \mathrm{M})$, and HeLa cells were treated with vehicle or compound $6(35 \mu \mathrm{M})$ for $48 \mathrm{~h}$. Cell cycle profile was determined by cell staining with propidium iodide and DNA content was assessed by flow cytometry. (C) Proportion of cells in the $\mathrm{G}_{2} / \mathrm{M}$ phase was expressed as a percentage of the total number of cells analyzed and represented as the means \pm standard error of the mean of at least three experiments. "P $<0.01$, one way analysis of variance with Tukey post-test comparing treated samples to the relevant untreated control. $\mathrm{IC}_{50}$, half maximal inhibitory concentration.

in the $\mathrm{G}_{2} / \mathrm{M}$ phase from $2.58 \pm 3.1 \%$ (control) to $24.59 \pm 2.4 \%$. Similarly, WM115 cell treatment with compound 6 increased cell population in the $\mathrm{G}_{2} / \mathrm{M}$ from $12.49 \pm 2.6 \%$ (control) to
$23.93 \pm 4.2 \%$. In cervical cancer cells, compound 6 treatment increased the $\mathrm{G}_{2} / \mathrm{M}$ phase cell population from $13.23 \pm 3.5 \%$ (control) to $24.17 \pm 5.6 \%$. Notably, whereas no significant effects of compound 6 were observed on the $\mathrm{S}$ phase of melanoma cells, HeLa cells treated with compound 6 exhibited a significant increase in the $\mathrm{S}$ phase cell population which raised from $9.24 \pm 2.3 \%$ (control) to $23.37 \pm 4.8 \%$. These results suggested that compounds (5-7), particularly compound 6 , may inhibit cancer cells proliferation and induce $\mathrm{G}_{2} / \mathrm{M}$ cell cycle arrest in cancer cells.

Compound 6 induces intrinsic apoptosis. To determine whether compound 6 induced apoptotic cell death, melanoma and cervical cancer cells were treated with 10 and $35.0 \mu \mathrm{M}$ compound 6 , respectively, for $48 \mathrm{~h}$ and stained with PI and Annexin V-FITC. The results from flow cytometry demonstrated that compound 6 significantly increased apoptosis in all cancer cell lines (Fig. 3A). In addition, the levels of apoptotic melanoma cells were higher than the levels of apoptotic HeLa cells following compound 6 treatment. A375 cells treated with $10 \mu \mathrm{M}$ of compound 6 for $48 \mathrm{~h}$ increased significantly from $4.58 \pm 2.34 \%$ (control) to $27.38 \pm 3.4 \%$. Similar results were obtained for WM115 cells that exhibited an increase in apoptosis from $3.48 \pm 1.49 \%$ (control) to $22.49 \pm 3.23 \%$ following 48 -h treatment with $10 \mu \mathrm{M}$ compound 6. However, the level of apoptosis induced by $35 \mu \mathrm{M}$ compound 6 was only $16.38 \pm 3.23 \%$ in HeLa cells. In addition, following nuclear staining and fluorescence microscopy analysis, cancer cells treated with compound 6 exhibited fragmented chromatin, which was characteristic of apoptotic cells (Fig. 3B). To further confirm that compound 6 induced apoptosis at a molecular level, and to investigate the mechanisms underlying compound 6-induced cell death, western blotting of key apoptotic proteins, including cleaved PARP, BAX, BCL2 and caspase-9 were performed (Fig. 3C). The results demonstrated that PARP cleavage was increased in all cancer cell lines following 24 and $48 \mathrm{~h}$ of treatment with compound 6. Furthermore, the markers of intrinsic apoptosis, including BAX cleaved caspase-9, were increased in the three cancer cell lines following $48 \mathrm{~h}$ of treatment with compound 6. In addition, the level of the anti-apoptotic protein BCL2 decreased in all treated cells. These results indicated that compound 6 induced intrinsic apoptotic pathways in melanoma and cervical cancer cell lines.

Compound 6 inhibits AKT/mTOR pathway. Previous studies have reported the ability of different imidazo[1,2-a]pyridines to inhibit AKT/mTOR pathway in cancer cells $(12,13)$. These studies demonstrated that these compounds bind to the ATP-binding site of PI3K with a high affinity, which induces the PI3K/AKT/mTOR pathway inhibition. To investigate whether compound 6 exerts its effect through the same mechanism, western blotting of key proteins from this pathway, including p-AKT (using the specific antibody for phosphorylated Ser 473 of Akt1), AKT and p-mTOR were performed. The results demonstrated that both p-AKT and p-mTOR levels were reduced in all cancer cells following 48-h treatment with compound 6 (Fig. 4A). These results indicated that compound 6 inhibited AKT, which may regulate other important proteins, including as p53. 
A

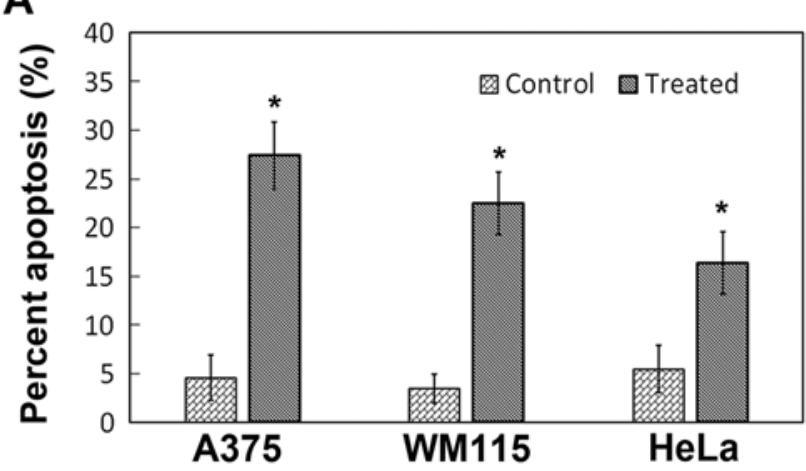

B

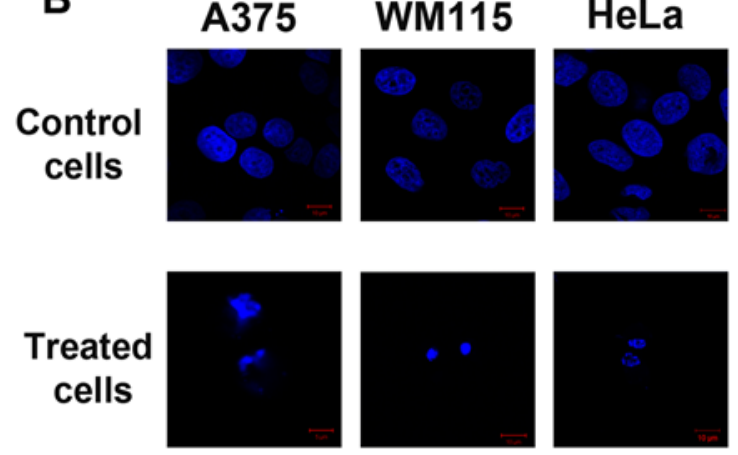

C

A375

WM115

HeLa

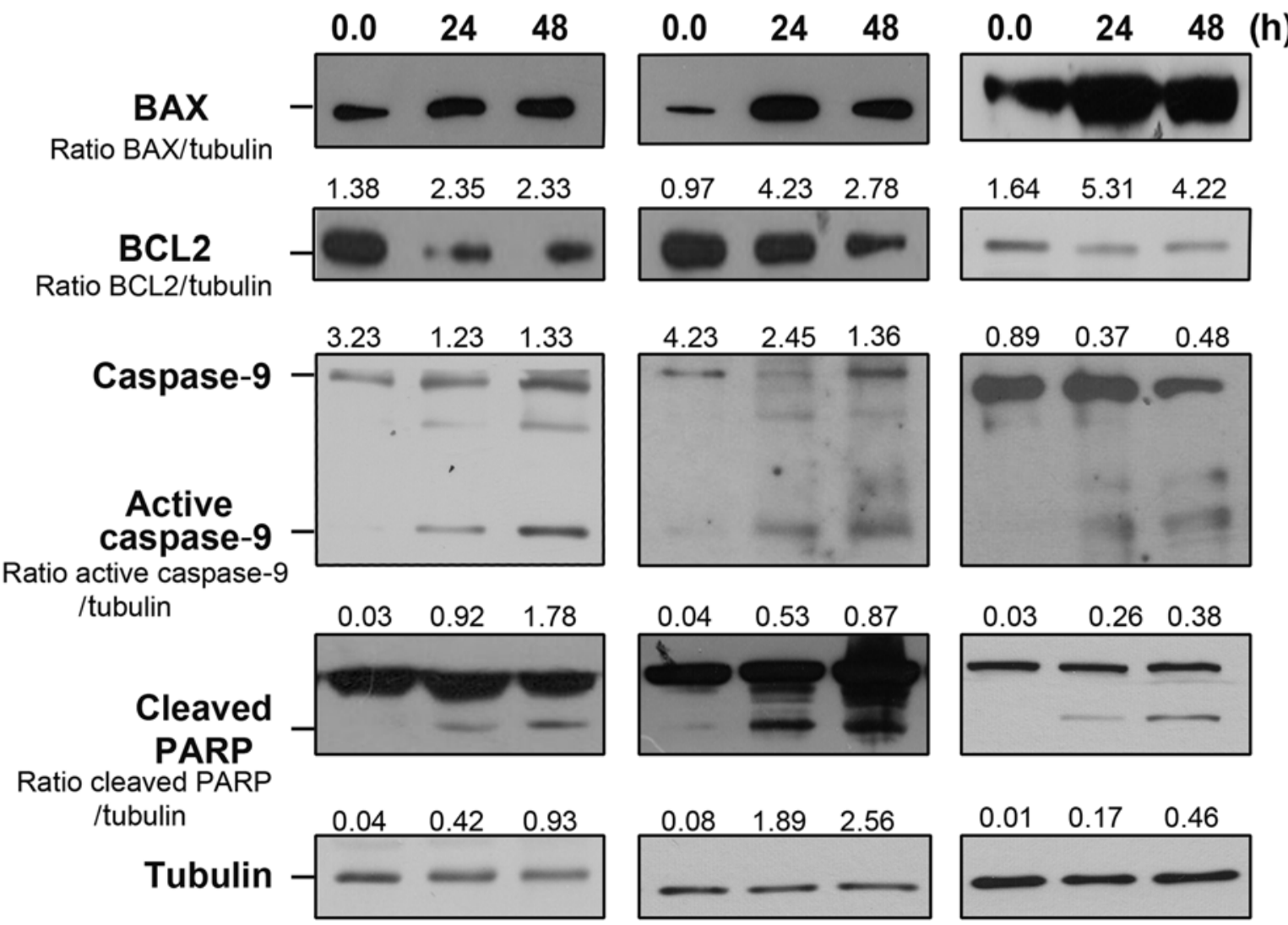

Figure 3. Compound 6 activates intrinsic apoptosis. (A) Flow cytometry analyses of Annexin V-fluorescein isothiocyanate/propidium iodide staining presented the apoptosis induction in melanoma and cervical cells treated with compound 6 at 10 and $35 \mu \mathrm{M}$, respectively, for $48 \mathrm{~h}$. The graph represented the percentage of cells undergoing apoptosis (early and late) and the results are presented as the mean of three independent experiments \pm standard error of the mean. ${ }^{*} \mathrm{P}<0.05$. (B) Fluorescence microscopy demonstrated that cancer cells treated as in (A) and stained with DAPI displayed fragmented chromatin characteristic of apoptotic cells. (C) Western blotting of proteins from cancer cells treated as in (A) presented BAX, BCL2, caspase-9 and cleaved PARP levels. BCL2, B-cell lymphoma 2; BAX, BCL2 associated X protein; FITC, fluorescein isothiocyanate, PARP, poly(ADP-ribose) polymerase.

p53 partially mediates compound 6 cytotoxicity. A previous study revealed that AKT facilitates p53 degradation by increasing MDM2 proto-oncogene expression (19). The effect of compound 6 on p53 response was therefore investigated. To do so, western blotting of p53 and its downstream target p21was performed. As presented in Fig. 4A, p53 and p21 protein levels were increased in all cancer cells following treatment with compound 6 . In addition, treatment with compound 6 reduced cyclin B level in all cancer cells which supports the $\mathrm{G}_{2} / \mathrm{M}$ cell cycle arrest detected as shown in Fig. 2B and C. The potential roles of p53-mediated signaling in compound 6 -induced cell death were investigated by inhibiting p53 expression via si-RNA transfection. A375 cells transfected with sip53 presented attenuated p21 expressions in control and compound 6-treated cells (Fig. 4B). This was further evidenced by the decreased level of cleaved PARP observed following compound 6 treatment in A375 sip53 cells (Fig. 4B). These observations were reinforced by Annexin V assay, which demonstrated that compound 6 treatment induced a moderate increase in apoptosis $(15.65 \pm 3.23 \%)$ in A375 sip53 cells, compared with un-transfected cells $(34.23 \pm 3.45 \%)$ (Fig. 4C). These observations suggested that compound 6 may induce apoptosis partly through p53 regulation. 
A

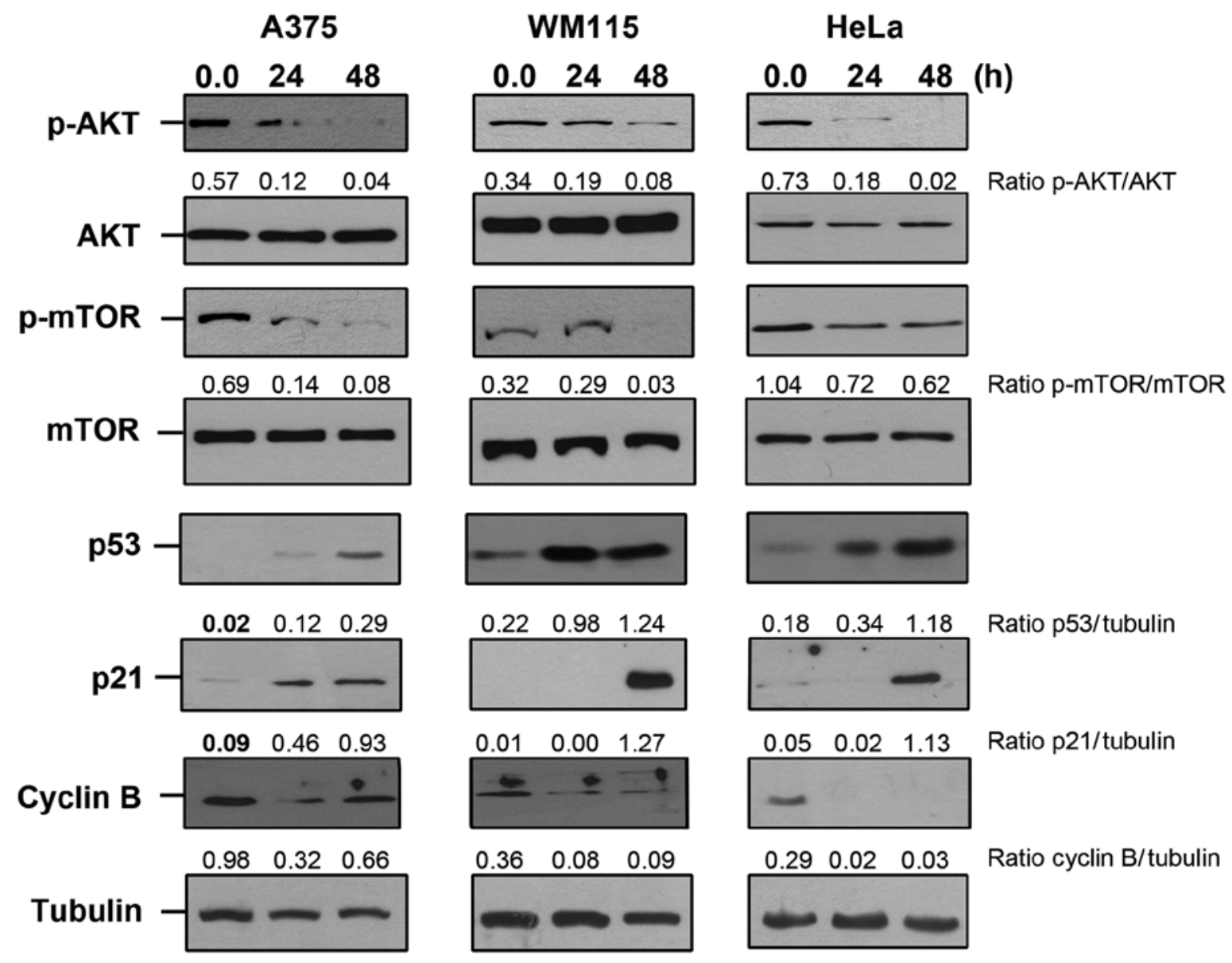

B

C

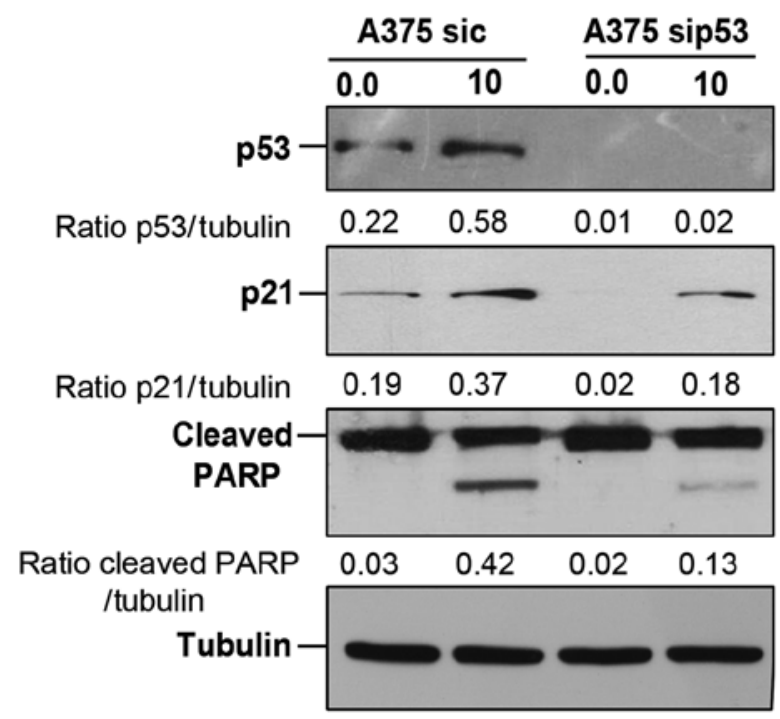

Compound $6(\mu \mathrm{M})$

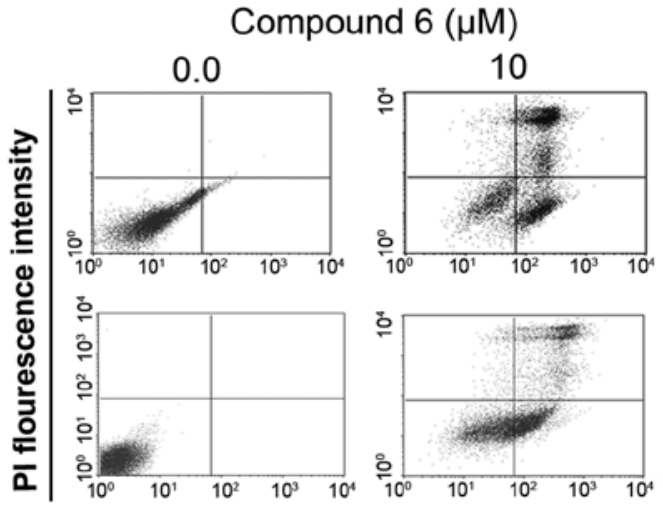

Annexin flourescence intensity

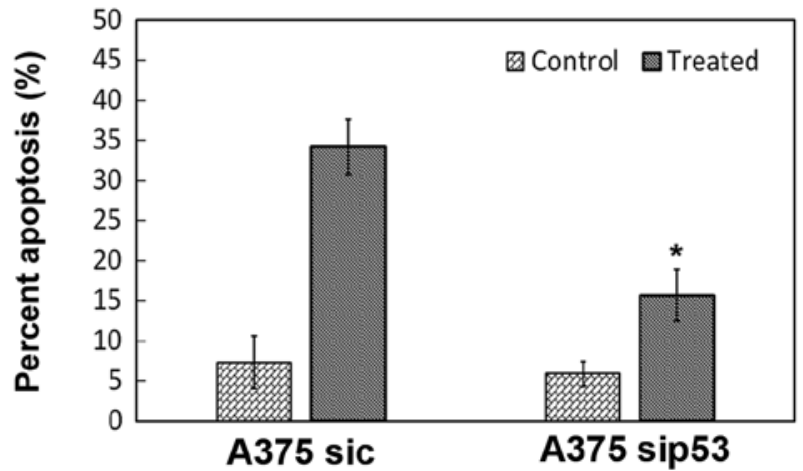

Figure 4. Compound 6 inhibits AKT/mTOR pathway and induces p53 dependent apoptosis. (A) Melanoma cells and HeLa cells were treated with vehicle or compound 6 at 10 and $35 \mu \mathrm{M}$, respectively, for $48 \mathrm{~h}$. p-AKT, AKT, p-mTOR, p53, p21, cyclin B and tubulin proteins were analyzed by western blotting. (B) A375 cells were transfected with sip53 and treated with compound $6(10 \mu \mathrm{M})$ for $48 \mathrm{~h}$. Protein extracts were harvested and p53, p21 and PARP were analyzed by western blotting. (C) Annexin V/propidium iodide double staining exhibited a percentage of cell death induced by compound 6 after sip53 transfection lower than in the un-transfected group (B). ${ }^{*} \mathrm{P}<0.05$. AKT, protein kinase B; c, control; mTOR, mechanistic target of rapamycin; p, phospho; si, small interfering. 


\section{Discussion}

The PI3K-AKT signaling pathway is one of the most investigated cascades in cancer cells. Increasing evidence has confirmed the crucial role of the PI3K-AKT pathway in cancer initiation and progression (18). The phosphatase and tensin homolog (PTEN) tumor suppressor is the most common regulator of this pathway, and tumors exhibiting PTEN loss usually have a high p-AKT level (20). In vitro and in vivo investigations have demonstrated that tumors with mutant proto-oncogene B-Raf (BRAF) also present high p-AKT levels, which may contribute to the development of BRAF-inhibitor resistance $(19,20)$. Similarly, PI3K-AKT pathway is commonly dysregulated in cervical cancer, which indicates that it may be a potential therapeutic target in the treatment of melanoma and cervical cancer (21). Numerous PI3K inhibitors have been developed and recently evaluated in clinical trials. These comprise PI3K specific inhibitors and dual targets inhibitors, including PI3K-mTOR and AKT inhibitors $(11,22)$. Subsequently, some imidazo[1,2-a]pyridine compounds were developed and tested for their PI3K-AKT pathway inhibiting ability (23-25). Our group has therefore designed and synthesized novel imidazo[1,2-a]pyridines (compounds 5-7) (15). The current study, aimed to investigate the exact anticancer effect of these compounds in melanoma and cervical cancer cells. Notably, compound 6 exhibited the most potent cytotoxic effect in both types of cancer cell. The anticancer effect of compound 6 and its mechanism of action in melanoma and cervical cancer cell lines were therefore deeper examined. The results from this study suggested that compound 6 may be considered as a promising novel chemotherapeutic drug for melanoma and cervical cancers treatment.

Compound 6 exhibited potent cytotoxicity in A375 and WM115 cell lines with low $\mathrm{IC}_{50}$ values $(<12 \mu \mathrm{M})$, which was of crucial importance, considering that metastatic melanoma cells seem to be resistant to chemotherapy. For example, the dose of dacarbazine, which is the common current treatment of metastatic melanoma, necessary to inhibit melanoma cell proliferation is $\sim 25 \mu \mathrm{M}$ (18). However, some imidazo[1,2a]pyridines presented similar or more potent cytotoxicity against melanoma cancer cells $(23,24)$. A novel series of imidazo[1,2-a]pyridine compounds inhibit A375 human melanoma cell line proliferation with a low $\mathrm{IC}_{50}<1 \mu \mathrm{M}$ (23). A recent study that screened the cytotoxic effects of novel pyrido-imidazodiazepinones reported that seven of these compounds significantly inhibit melanoma cell growth at $1 \mu \mathrm{M}(24)$.

In the present study, cancer cell treatment with compound 6 induced a decrease in p-AKT level. This effect was observed after $24 \mathrm{~h}$ in HeLa cells, and was even more important following 48-h treatment with compound 6 in melanoma cells. Notably, AKT inhibition was mirrored with the inhibition of its downstream target mTOR. Previous studies have reported that AKT and target m-TOR inhibitions increase p21 expression and activate checkpoint kinase 2 , which results in $\mathrm{G}_{2} / \mathrm{M}$ cell cycle arrest (26-28). Furthermore, these studies showed that the blockage of cell cycle arrest at the $\mathrm{G}_{2} / \mathrm{M}$ phase is associated with a decrease in the cell cycle regulatory protein cyclin B level. Similarly, the results from the present study demonstrated that compound 6 induced a decrease in cyclin B1 level.
Notably, compound 6 increased p53 and p21 levels, which could explain the $\mathrm{G}_{2} / \mathrm{M}$ cell cycle arrest observed.

The PI3K/AKT/mTOR pathway is involved in cell survival, and its inhibition results in high p53 and BAX apoptotic proteins levels (18). Active BAX disrupts the mitochondrial membrane integrity and induces the cytochrome $c$ release from mitochondria into the cytosol. Cytoplasmic cytochrome $\mathrm{c}$ and active caspase- 9 are then involved in the apoptosome formation and caspase-3 activation (29). However, cytochrome c release does not happen when the anti-apoptotic protein BCL2 is present. The present study demonstrated that compound 6 stimulated intrinsic apoptosis by increasing BAX and active caspase-9 levels, and decreasing BCL2 level. The results suggested that the $\mathrm{G}_{2} / \mathrm{M}$ cell cycle arrest and intrinsic apoptosis induced by compound 6 may be mediated by AKT/mTOR inhibition. Notably, p53 silencing significantly decreased the compound 6-induced apoptosis, which suggested that p53 may serve an important role in compound 6-induced cell apoptosis. Numerous imidazopyridine derivatives are currently used in the clinic for the treatment of other diseases, including alpidem (anxiolytic) and zolpidem (hypnotic), which exhibit low toxicity levels (30). This could indicate that the compounds tested in the present study may present minor adverse effects.

\section{Acknowledgements}

Not applicable.

\section{Funding}

The present study was supported by the Qatar Charity under the Ibhath project for research grants, which is funded by the Cooperation Council for the Arab States of the Gulf through the Islamic Development Bank.

\section{Availability of data and materials}

All data generated or analyzed during this study are included in this published article.

\section{Authors' contributions}

SA designed the biological study, supervised different steps and was the major contributor in the writing of the manuscript. AMA synthesized and tested the chemical compounds. RYM supervised and characterized the synthesized compounds. MG contributed to the tissue culture experiments. HA contributed to the tissues culture, western blotting experiments and cell cycle analysis. AYA contributed to the western blotting and tissue culture experiments. EAA contributed to the western blotting experiments. YMA contributed to the apoptosis assay. All authors read and approved the final manuscript.

\section{Ethics approval and consent to participate}

Not applicable.

\section{Patients consent for publication}

Not applicable. 


\section{Competing interests}

The authors declare that they have no competing interests.

\section{References}

1. Bray F, Ferlay J, Soerjomataram I, Siegel R, Torre L and Jemal A: Global cancer statistics 2018: GLOBOCAN estimates of incidence and mortality worldwide for 36 cancers in 185 countries. CA Cancer J Clin 68: 394-424, 2018.

2. Chen YJ and Del Priore G: The role of cisplatin alternative regimens with radiotherapy in cervical cancer. Gynecol Oncol Rep 11: 38-40, 2014.

3. Schadendorf D, Fisher DE, Garbe C, Gershenwald JE, Grob JJ, Halpern A, Herlyn M, Marchetti MA, McArthur G, Ribas A, et al Melanoma. Nat Rev Dis Primers 1: 15003, 2015.

4. Patel PM, Suciu S, Mortier L, Kruit WH, Robert C, SchadendorfD, Trefzer U, Punt CA, Dummer R, Davidson N, et al: Extended schedule, escalated dose temozolomide versus dacarbazine in stage IV melanoma: Final results of a randomised phase III study (EORTC 18032). Eur J Cancer 47: 1476-1483, 2011.

5. Long GV, Stroyakovskiy D, Gogas H, Levchenko E, de Braud F, Larkin J, Garbe C, Jouary T, Hauschild A, Grob JJ, et al: Combined BRAF and MEK Inhibition versus BRAF inhibition alone in melanoma. N Engl J Med 371: 1877-1888, 2014.

6. Sosman JA, Kim KB, Schuchter L, Gonzalez R, Pavlick AC, Weber JS, McArthur GA, Hutson TE, Moschos SJ, Flaherty KT, et al: Survival in BRAF V600-mutant advanced melanoma treated with vemurafenib. N Engl J Med 366: 707-714, 2012.

7. Kim O, Jeong Y, Lee H, Hong SS and Hong S: Design and synthesis of imidazopyridine analogues as inhibitors of phosphoinositide 3-kinase signaling and angiogenesis. J Med Chem 54: 2455-2466, 2011.

8. Ducray R, Jones CD, Jung FH, Simpson I, Curwen J and Pass M: Novel imidazo[1,2-a]pyridine base $d$ inhibitors of the IGF-1 receptor tyrosine kinase: Optimization of the aniline. Bioorg Med Chem Lett 21: 4702-4704, 2011.

9. Goel R, Luxami V and Paul K: Imidazo[1,2-a]pyridines: Promising drug candidate for antitumor therapy. Curr Top Med Chem 16: 3590-3616, 2016.

10. Hayakawa M, Kawaguchi K, Kaizawa H, Koizumi T, Ohishi T, Yamano M, Okada M, Ohta M, Tsukamoto S, Raynaud FI, et al: Synthesis and biological evaluation of sulfonylhydrazone-substituted imidazo[1,2-a]pyridines as novel PI3 kinase p110alpha inhibitors. Bioorg Med Chem 15: 5837-5844, 2007.

11. Lee H, Kim SJ, Jung KH, Son MK, Yan HH, Hong S and Hong SS: A novel imidazopyridine PI3K inhibitor with anticancer activity in non-small cell lung cancer cells. Oncol Rep 30: 863-869, 2013.

12. Almeida GM, Rafique J, Saba S, Siminski T, Mota NSRS Filho DW, Braga AL, Pedrosa RC and Ourique F: Novel selenylated imidazo[1,2-a]pyridines for breast cancer chemotherapy: Inhibition of cell proliferation by Akt-mediated regulation, DNA cleavage and apoptosis. Biochem Biophys Res Commun 503: 1291-1297, 2018.

13. Zheng X, Bauer P, Baumeister T, Buckmelter AJ, Caligiuri M, Clodfelter KH, Han B, Ho YC, Kley N, Lin J, et al: Structure-based discovery of novel amide-containing nicotinamide phosphoribosyltransferase (Nampt) inhibitors. J Med Chem 56: 6413-6433, 2013.

14. Cai D, Byth KF and Shapiro GI: AZ703, an imidazo[1,2-a] pyridine inhibitor of cyclin-dependent kinases 1 and 2 , induces E2F-1-dependent apoptosis enhanced by depletion of cyclin-dependent kinase 9. Cancer Res 66: 435-444, 2006.

15. Morjan RY, Qeshta BS, Al-Shayyah HT, Gardiner JM, Abu-Thaher BA and Awadallah AM: Reaction of nitrilimines with 5-aminotetrazole and 2-aminopyrimidine. Int J Org Chem 4: 201-207, 2014.

16. Aliwaini S, Swarts AJ, Blanckenberg A, Mapolie S and Prince S A novel binuclear palladacycle complex inhibits melanoma growth in vitro and in vivo through apoptosis and autophagy. Biochem Pharmacol 86: 1650-1663, 2013.
17. Al-Qatati A and Aliwaini S: Combined pitavastatin and dacarbazine treatment activates apoptosis and autophagy resulting in synergistic cytotoxicity in melanoma cells. Oncol Lett 14: 7993-7999, 2017.

18. Davies MA, Stemke-Hale K, Lin E, Tellez C, Deng W, Gopal YN, Woodman SE, Calderone TC, Ju Z, Lazar AJ, et al: Integrated molecular and clinical analysis of AKT activation in metastatic melanoma. Clin Cancer Res 15: 7538-7546, 2010.

19. Astle MV, Hannan KM, Ng PY, Lee RS, George AJ, Hsu AK, Haupt Y, Hannan RD and Pearson RB: AKT induces senescence in human cells via mTORC1 and p53 in the absence of DNA damage: Implications for targeting mTOR during malignancy. Oncogene 31: 1949-1962, 2012.

20. Vasudevan KM, Barbie DA, Davies MA, Rabinovsky R, McNear CJ, Kim JJ, Hennessy BT, Tseng H, Pochanard P, Kim SY, et al: AKT-independent signaling downstream of oncogenic PIK3CA mutations in human cancer. Cancer Cell 16: 21-32, 2009.

21. Bahrami A, Hasanzadeh M, Hassanian SM, ShahidSales S, Ghayour-Mobarhan M, Ferns GA and Avan A: The potential value of the PI3K/Akt/mTOR signaling pathway for assessing prognosis in cervical cancer and as a target for therapy. J Cell Biochem 118: 4163-4169, 2017.

22. Yang L, Dan HC, Sun M, Liu Q, Sun X, Feldman RI,Hamilton AD, Polokoff M, Nicosia SV, Herlyn M, et al: Akt/Protein kinase B signaling inhibitor-2, a selective small molecule inhibitor of Akt signaling with antitumor activity in cancer cells overexpressing Akt. Cancer Res 64: 4394-4399, 2004.

23. Garamvölgyi R, Dobos J, Sipos A, Boros S, Illyés E, Baska F, Kékesi L, Szabadkai I, Szántai-Kis C, Kéri G and Ốrfi L: Design and synthesis of new imidazo[1,2-a]pyridine and imidazo[1,2-a] pyrazine derivatives with antiproliferative activity against melanoma cells. Eur J Med Chem 108: 623-643, 2016.

24. Bellet V, Lichon L, Arama DP, Gallud A, Lisowski V, Maillard LT, Garcia M, Martinez J and Masurier N: Imidazopyridine-fused [1,3]-diazepinones part 2: Structure-activity relationships and antiproliferative activity against melanoma cells. Eur J Med Chem 125: 1225-1234, 2017.

25. Ingersoll MA, Lyons AS, Muniyan S, D'Cunha N, Robinson $T$, Hoelting K, Dwyer JG, Bu XR, Batra SK and Lin MF: Novel imidazopyridine derivatives possess anti-tumor effect on human castration-resistant prostate cancer cells. PLoS One 10: e0131811, 2015.

26. Kuo PL, Hsu YL and Cho CY: Plumbagin induces G2-M arrest and autophagy by inhibiting the AKT/mammalian target of rapamycin pathway in breast cancer cells. Mol Cancer Ther 5: 3209-3221, 2006.

27. Chang MC, Chen YJ, Liou EJ, Tseng WY, Chan CP, Lin HJ, Liao WC, Chang YC, Jeng PY and Jeng JH: 7-Ketocholesterol induces ATM/ATR, Chk1/Chk2, PI3K/Akt signaling, cytotoxicity and IL-8 production in endothelial cells. Oncotarget 7: 74473-74483, 2016.

28. Hirose Y, Katayama M, Mirzoeva OK, Berger MS and Pieper RO: Akt activation suppresses Chk2-mediated, methylating agent-induced $\mathrm{G} 2$ arrest and protects from temozolomideinduced mitotic catastrophe and cellular senescence. Cancer Res 65: 4861-4869, 2005.

29. Aliwaini S, Peres J, Kröger WL, Blanckenberg A, de la Mare J, Edkins AL, Mapolie S and Prince S: The palladacycle, AJ-5, exhibits anti-tumour and anti-cancer stem cell activity in breast cancer cells. Cancer Lett 357: 206-218, 2015.

30. Hanson SM, Morlock EV, Satyshur KA and Czajkowski C: Structural requirements for eszopiclone and zolpidem binding to the gamma-aminobutyric acid type-A (GABAA) receptor are different. J Med Chem 51: 7243-7252, 2008.

This work is licensed under a Creative Commons Attribution-NonCommercial-NoDerivatives 4.0 International (CC BY-NC-ND 4.0) License. 